\title{
Long-term results of the iBP elbow prosthesis: beware of destructive metallosis!
}

Daniëlle Meijering $^{1 *}$, Alexander L. Boerboom ${ }^{1}$, Fred Breukelman ${ }^{2}$, Denise Eygendaal ${ }^{3,4}$, Sjoerd K. Bulstra ${ }^{1}$ and Martin Stevens ${ }^{1}$

\begin{abstract}
Background: The aim of this study was to review the long-term results of the instrumented Bone Preserving (iBP) elbow prosthesis.

Methods: Thirty-one patients (10 M, 21F, 28-77 year) were retrospectively evaluated using the Oxford Elbow Score (OES), Disabilities of Arm, Shoulder and Hand Outcome Measure (DASH), Mayo Elbow Performance (MEPS), physical examination and standard radiographs. Kaplan-Meier survival analysis was used.

Results: Thirty-seven primary iBPs have been placed in 31 patients between 2000 and 2007. Six patients (8 prostheses) had died, 10 elbows had been revised and three patients (4 prostheses) were lost to follow-up. Fourteen patients (15 prostheses) were available for follow-up. The main indication for surgery was rheumatoid arthritis. Mean follow-up was 11 years (8-15). Kaplan-Meier survival analysis showed a survival of $81 \%$ at 10 years after surgery. Main reason for revision was particle disease and loosening due to instability and malalignment. Eleven of 14 patients were satisfied, although radiographs showed radiolucencies in 11 patients.
\end{abstract}

Conclusion: The iBP elbow prosthesis gives a survival rate of $81 \% 10$ years after surgery with a progressive decline beyond 10 years. However, many patients have radiolucencies. Discrepancy between clinical signs and radiological results warrants structural follow-up, to assure quality of bone stock in case revision surgery is indicated.

The study was reviewed and approved by the Medical Ethical Committee of University Medical Center Groningen (METc2016/038).

Level of evidence: Level IV, Case series.

Keywords: iBP, Elbow prosthesis, Unlinked elbow prosthesis, arthroplasty, Long-term follow-up

\section{Background}

Joint destruction due to inflammatory arthritis is still the main reason for a total elbow arthroplasty (TEA), although nowadays posttraumatic osteoarthritis is a more common indication for a replacement $[1,2]$. As the prevalence of TEA is low compared to knee and hip arthroplasties, reports with long-term follow-up are rather scarce.

Over the last 40 years there have been many improvements in the design of total elbow prostheses. In general,

\footnotetext{
*Correspondence: d.meijering@umcg.nl

'Department of Orthopedic Surgery, University of Groningen, University

Medical Center Groningen, Groningen, the Netherlands

Full list of author information is available at the end of the article
}

three types of prostheses are available: unlinked devices, linked devices and convertible devices, which can be used as either a linked or an unlinked system. The instrumented Bone Preserving (iBP) (Biomet, Warsaw, IN, USA) elbow prosthesis is an unlinked, ulnohumeral prosthesis, designed by Pooley. The iBP elbow prosthesis is a modification of the Kudo type 5, developed to preserve more bone stock (Fig. 1) [3]. A study with a mean follow-up of 49 months by Kleinlugtenbelt et al. [4] showed a discrepancy between clinical outcome and radiological signs. Patients scoring good-to-excellent on the Mayo Elbow Performance Score (MEPS) did show radiolucencies around their ulnar component, while patients with a poor MEPS score did not. As a result of

(c) The Author(s). 2019 Open Access This article is distributed under the terms of the Creative Commons Attribution 4.0 International License (http://creativecommons.org/licenses/by/4.0/), which permits unrestricted use, distribution, and reproduction in any medium, provided you give appropriate credit to the original author(s) and the source, provide a link to the Creative Commons license, and indicate if changes were made. The Creative Commons Public Domain Dedication waiver (http://creativecommons.org/publicdomain/zero/1.0/) applies to the data made available in this article, unless otherwise stated. 


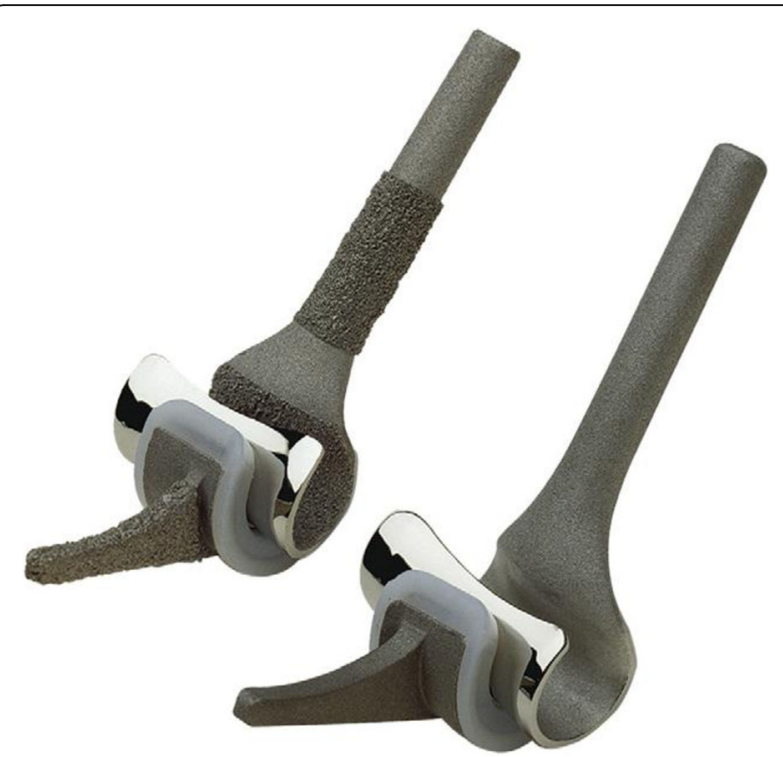

Fig. 1 iBP uncemented (left) and cemented (right) ulnar and humeral components

this discrepancy, progressive radiolucency can occur without any clinical symptoms, which results in bone loss, hampering the results of revision surgery. In a study with a mean follow-up of 7.5 years, Dalemans et al. [5] reported a drop in survival 6 years after surgery due to instability, infection and metallosis, but they did not see loosening of the components in their patients. The aim of this study was to assess the long-term results of the iBP elbow prosthesis.

\section{Methods}

Between April 2000 and June 200937 primary iBP total elbow arthroplasties in 31 patients have been performed at University Medical Center of Groningen by 4 different orthopedic surgeons. All 31 patients (37 elbows) with a primary iBP were included in this study. Nineteen elbows were left and 18 were right elbows. Mean age of the patients was 55 at the time of surgery. Ten patients were male, 21 female. Indications for surgery were painful destruction of the elbow joint due to rheumatoid arthritis in 23 patients (28 elbows), posttraumatic osteoarthritis in 3 patients and haemophilic arthropathy in 5 patients (6 elbows). Patients' characteristics are shown in Table 1.

The study was reviewed and approved by the Medical Ethical Committee of UMCG (METc2016/038). None of the surgeons was involved in the design of the implant.

\section{Surgical technique}

In all cases a posterior approach was used with a triceps split technique as described by Pooley $[3,6]$. The ulnar nerve was released and protected during the procedure.
Release of the collateral ligaments were performed in case of contractures. The radial head was excised in all cases. The humerus and ulna were prepared with preservation of as much bone as possible according to the philosophy of this prosthesis. All humeral components were inserted without cement, except for 6 elbow prostheses in which poor bone quality urged to the use of cement. All ulnar components were cemented.

Post-operatively the elbow was protected by a removable cast for 4 weeks, avoiding active extension. Thereafter, the elbow was mobilized without brace and active triceps training was allowed. Patients were advised to limit weight bearing up to $1 \mathrm{~kg}$ repetitively and to $5 \mathrm{~kg}$ incidentally.

\section{Outcome measures}

To assess pain, elbow function and social-psychological status, the Oxford Elbow Score (OES) [7] was used. Disabilities of Arm, Shoulder and Hand Outcome Measure (DASH) [8] was used to assess upper-limb function. The Mayo Elbow Performance Score (MEPS) [9] was used to assess pain, range of motion and stability. Health-related quality of life was determined by using the EQ. 5D-3 L VAS score [10]. Pain at rest and during activities was scored from 0 (no pain) to 10 (severe pain) using visual analogue scales (VAS). Patients were also asked whether they were satisfied with their elbow function. By means of physical examination we determined the active range of motion (ROM). The integrity of the ulnar nerve was assessed using careful clinical examination. The stability of the medial and lateral collateral ligaments was scored as grade 0 , no instability; grade 1 , moderate instability $\left(<10^{\circ}\right)$ and grade 2 severe instability $\left(>10^{\circ}\right)$. All patients had standard anteroposterior (AP) and lateral radiographs of the elbow. Loosening of the implants was classified using the system described by Wagener et al. [11] (Fig. 2). Radiographs were also assessed of dislocation of the prosthesis, subluxation, periprosthetic fractures and signs of metallosis.

\section{Statistical analysis}

SPSS statistical software (version 24.0, IBM SPSS, Chicago) was used. Descriptive statistics were used to describe patients' characteristics, clinical outcomes and scores on the questionnaires. Kaplan-Meier survival analysis was performed with revision as an end point. Kruskal-Wallis Test for independent samples was used to analyze differences in indication for surgery.

\section{Results}

The mean follow-up of this study is $11(8-15)$ years. At follow-up 6 patients ( 8 elbows) had died. Ten elbow prostheses in 10 patients had already been revised, leaving 19 primary prostheses in 17 patients in situ. Unfortunately, three patients (4 elbows) could not participate in our 
Table 1 Patient characteristics

\begin{tabular}{|c|c|c|c|c|c|c|c|c|c|c|c|c|c|}
\hline Patient & $\begin{array}{l}\text { Age } \\
\text { range }\end{array}$ & Etiology & Side & Fixation & $\begin{array}{l}\text { Survival } \\
\text { (years) }\end{array}$ & $\begin{array}{l}\text { Reason } \\
\text { Revision }\end{array}$ & OES & DASH & MEPS & Flexion & Extension & \multicolumn{2}{|l|}{ Complication } \\
\hline 1 & 3 & HA & $\mathrm{L}$ & $\mathrm{H}$ & 14 & & 40 & 42 & 60 & 70 & 30 & ULN & \\
\hline 2 & 3 & $\mathrm{RA}$ & $\mathrm{R}$ & $\mathrm{H}$ & 14 & & 42 & 69 & 90 & 135 & 20 & ULN & \\
\hline 3 & 1 & RA & $\mathrm{L}$ & $\mathrm{H}$ & 14 & & 22 & 70 & 70 & 130 & 25 & & \\
\hline 4 & 5 & HA & $\mathrm{R}$ & $\mathrm{H}$ & 12 & & 48 & 21 & 95 & 125 & 40 & & \\
\hline 5 & 3 & PTA & $\mathrm{L}$ & $\mathrm{H}$ & 9 & & 24 & 52 & 55 & 125 & 25 & & \\
\hline 6 & 5 & $\mathrm{RA}$ & $\mathrm{L}$ & $\mathrm{H}$ & 8 & & 39 & 32 & 85 & 125 & 30 & & \\
\hline 7 & 5 & RA & $\mathrm{R}$ & $\mathrm{C}$ & 15 & & 14 & 61 & 45 & 120 & 55 & & \\
\hline 8 & 3 & RA & $\mathrm{R}$ & $\mathrm{H}$ & 9 & & 35 & 50 & 75 & 115 & 50 & & \\
\hline \multirow[t]{2}{*}{9} & 4 & RA & $\mathrm{R}$ & $\mathrm{C}$ & 0 & INST & & & & & & & \\
\hline & 4 & & $\mathrm{~L}$ & $\mathrm{H}$ & 9 & & 37 & 54 & 90 & 130 & 30 & & \\
\hline \multirow[t]{2}{*}{10} & 3 & HA & $\mathrm{R}$ & $\mathrm{H}$ & 13 & MET & & & & & & ULN, INF & \\
\hline & 3 & & $\mathrm{~L}$ & $\mathrm{C}$ & 8 & & 16 & 42 & 70 & 115 & 70 & & \\
\hline 11 & 3 & RA & $\mathrm{R}$ & $\mathrm{H}$ & 9 & & 32 & 17 & 90 & 120 & 45 & & \\
\hline 12 & 5 & RA & $\mathrm{R}$ & $\mathrm{H}$ & 13 & & 43 & 46 & 100 & 130 & 30 & & \\
\hline \multirow[t]{2}{*}{13} & 4 & RA & $\mathrm{R}$ & $\mathrm{H}$ & 10 & & 39 & 28 & 95 & 140 & 30 & & \\
\hline & 4 & & $\mathrm{~L}$ & $\mathrm{H}$ & 9 & & 38 & 28 & 100 & 145 & 35 & & \\
\hline 14 & 5 & RA & $\mathrm{R}$ & $\mathrm{C}$ & 15 & & 42 & 45 & 75 & 130 & 5 & & \\
\hline 15 & 4 & $\mathrm{RA}$ & $\mathrm{R}$ & $\mathrm{H}$ & 11 & & & & & & & & \\
\hline 16 & 3 & PTA & $\mathrm{L}$ & $\mathrm{C}$ & 15 & MET & & & & & & DIS & \\
\hline 17 & 2 & $\mathrm{RA}$ & $\mathrm{R}$ & $\mathrm{H}$ & 13 & MET & & & & & & & \\
\hline \multirow[t]{2}{*}{18} & 6 & RA & $\mathrm{R}$ & $\mathrm{H}$ & 14 & & & & & & & DIS & $\dagger$ \\
\hline & 6 & & $\mathrm{~L}$ & $\mathrm{H}$ & 10 & & & & & & & ULN & $\dagger$ \\
\hline 19 & 3 & RA & $\mathrm{L}$ & $\mathrm{H}$ & 8 & & & & & & & & $\dagger$ \\
\hline 20 & 3 & $\mathrm{RA}$ & $\mathrm{L}$ & $\mathrm{H}$ & 2 & $\mathrm{AL}$ & & & & & & & 1 \\
\hline 21 & 3 & HA & $\mathrm{L}$ & $\mathrm{H}$ & 13 & MET & & & & & & & \\
\hline 22 & 4 & RA & $\mathrm{L}$ & $\mathrm{H}$ & 4 & INST & & & & & & & \\
\hline 23 & 6 & RA & $\mathrm{R}$ & $\mathrm{H}$ & 7 & & & & & & & & $\dagger$ \\
\hline 24 & 6 & RA & L & $\mathrm{H}$ & 1 & & & & & & & & $\dagger$ \\
\hline \multirow{2}{*}{25} & 5 & RA & $\bar{L}$ & $\mathrm{H}$ & 3 & & & & & & & ULN & $\dagger$ \\
\hline & 5 & & $\mathrm{R}$ & $\mathrm{H}$ & 2 & & & & & & & & $\dagger$ \\
\hline 26 & 6 & PTA & $\mathrm{R}$ & $\mathrm{H}$ & 10 & MET & & & & & & & \\
\hline \multirow[t]{2}{*}{27} & 4 & RA & $\mathrm{L}$ & $\mathrm{H}$ & 11 & & & & & & & & \\
\hline & 4 & & $\mathrm{R}$ & $\mathrm{H}$ & 9 & & & & & & & & \\
\hline 28 & 3 & RA & L & $\mathrm{H}$ & 7 & & & & & & & INF & $\dagger$ \\
\hline 29 & 4 & $\mathrm{RA}$ & $\mathrm{L}$ & $\mathrm{H}$ & 2 & INF & & & & & & & \\
\hline 30 & 5 & $\mathrm{HA}$ & $\mathrm{L}$ & $\mathrm{H}$ & 2 & $\mathrm{AL}$ & & & & & & & \\
\hline 31 & 4 & RA & $\mathrm{R}$ & C & 16 & & & & & & & & \\
\hline Med & 4 & $\begin{array}{l}23 \mathrm{RA} \\
3 \mathrm{PTA} \\
5 \mathrm{HA}\end{array}$ & & & 11 & & 38 & 45 & 85 & 125 & 30 & & \\
\hline
\end{tabular}

Age range (years): $1=20-29,2=30-39,3=40-49,4=50-59,5=60-69,6=70-79$,

HA haemophilic arthropathy, RA rheumatoid arthritis, PTA post-traumatic arthritis, $C$ cemented, $H$ hybrid (humeral component cementless), $A L$ aseptic loosening, INF infection, INST instability, MET metallosis, ULN ulnaropathy, DIS = dislocation, $\dagger=$ died

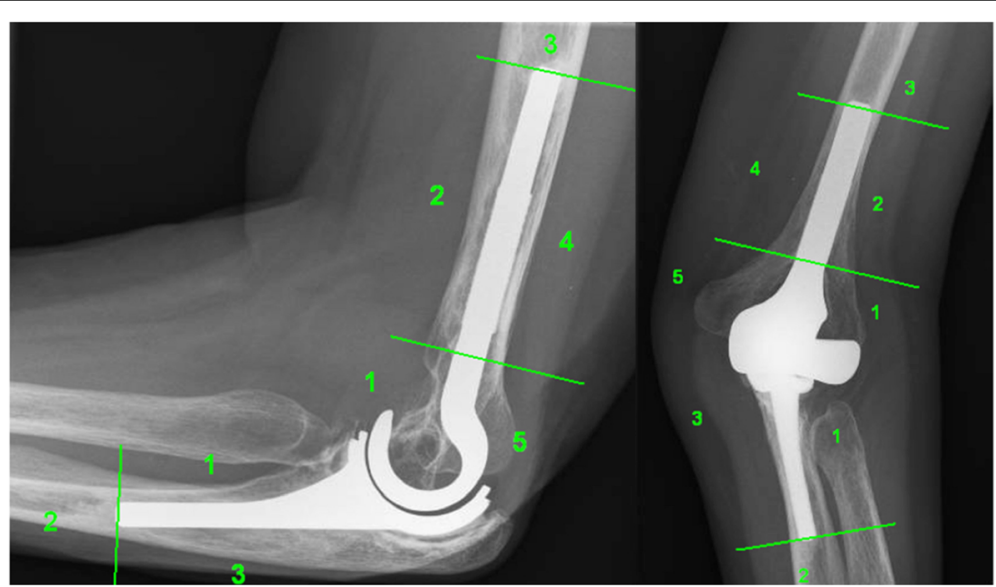

Fig. 2 Classification of radiological analysis as described by Wagener et al. In each zone we looked for the presence of radiolucencies 
follow-up, as they were physically unable to come to the hospital. However, they did not have complaints of their elbow. Fourteen patients with 15 primary iBP elbow prostheses were available for clinical assessment (Fig. 3).

\section{Survival}

The Kaplan-Meier survival analysis (Fig. 4) showed survival rates of 88 and $81 \%$ respectively at 5 and 10 years after surgery. All 37 primary iBP's were included in this analysis. Furthermore, a progressive decline in survival is visible beyond 10 years. Ten out of $37 \mathrm{iBP}$ elbow prostheses had been revised. The reasons for early revision were infection in one patient, aseptic loosening in two patients and instability in two patients, which occurred in the first 4 years after surgery. The reason for late revision (after 9 years) was loosening with severe polyethylene wear and as a consequence metallosis in 5 patients (Figs. 5,6). Arrows show radiolucency (orange) around the prosthesis and severe pseudotumor (blue), indicating metallosis.

\section{Clinical assessment}

Overall, most patients were satisfied with their iBP elbow prosthesis. Only 2 out of 14 patients were not satisfied with the result. One patient was not satisfied, because of ulnar neuropathy and loss of function. Another patient was no longer satisfied because of loosening of the ulnar component that had led to loss of function. No revision arthroplasty was planned though because of severe comorbidities. One patient was indifferent, which left 11 patients (12 elbows) being satisfied with their iBP elbow prosthesis.

Mean MEPS score was 80 points (45-100) indicating a fair-to-good result. Lower scores indicated pain in most cases. Mean DASH score was 44 points (17-70) and mean
OES 34 points (14-48). This score usually indicates mildto-moderate elbow complaints. The underlying disease, rheumatoid arthritis, mainly influenced both scores, as illustrated by the health-related quality of life score: 6 (4-8). Assessment of pain on a $0-10$ point scale scored a mean of 2 (0-7), indicating low pain levels.

Mean ROM was $90^{\circ}\left(40^{\circ}-125^{\circ}\right)$, mean flexion $125^{\circ}$ $\left(70^{\circ}-145^{\circ}\right)$, mean extension deficit $35^{\circ}\left(5^{\circ}-70^{\circ}\right)$. Mean pronation $70^{\circ}\left(40^{\circ}-95^{\circ}\right)$, mean supination $75^{\circ}\left(40^{\circ}-95^{\circ}\right)$. Seven out of 15 elbows were unstable. Two of them were grossly unstable and 5 were moderately unstable, although this was not clinically relevant in terms of dislocation. Three of 14 patients had signs of persistent ulnar neuropathy. There were no significant differences in clinical outcomes and survival between indication for surgery.

\section{Radiological assessment}

At the assessment, one out of 15 cases showed loosening of the ulnar component with a fracture in zone 3. Eleven out of 15 cases showed radiolucent lines, especially in zones 1 and 3 of the ulna. Three cases showed incongruity and another 3 cases showed signs of metallosis and pseudotumor (Table 2). Looking back at the already revised cases, 5 of 10 cases (all late revisions) had severe radiolucencies (especially zones 1 and 3 of the ulna) and signs of metallosis, which was confirmed at revision surgery.

All together in 15 of 25 cases (revisions and survivals) the radiographs indicated bone loss due to particle disease with PE wear and metallosis as to be expected. The case shown in Fig. 5 demonstrated radiolucencies and pseudotumor, suggestive for metallosis. Painful loosening 10 years after primary surgery led to a revision in which severe bone loss was encountered.

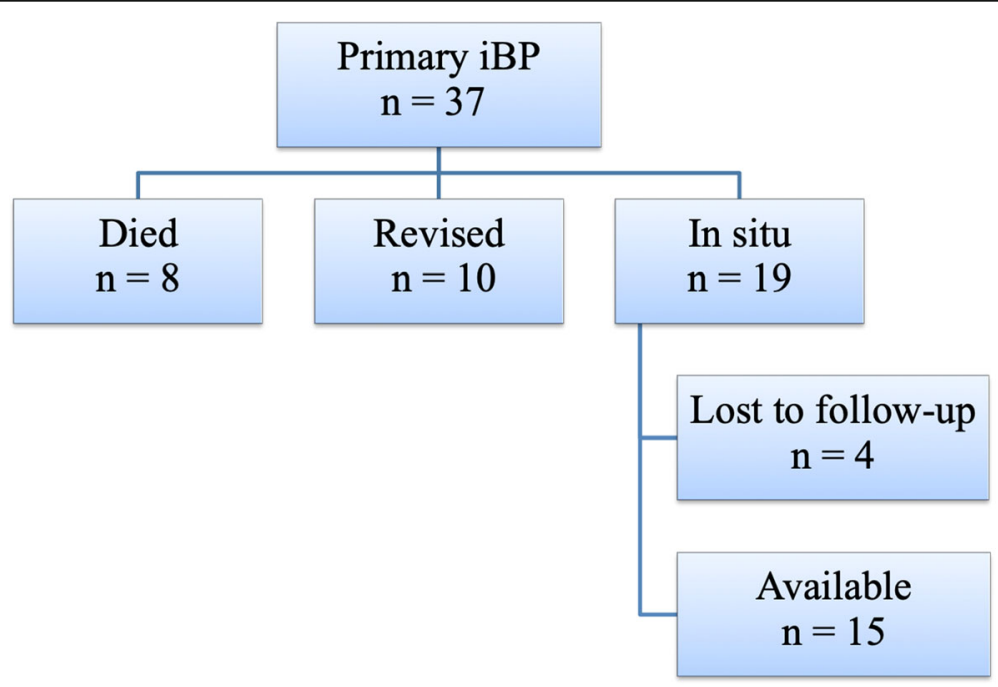

Fig. 3 Flow diagram of iBP elbow prostheses 


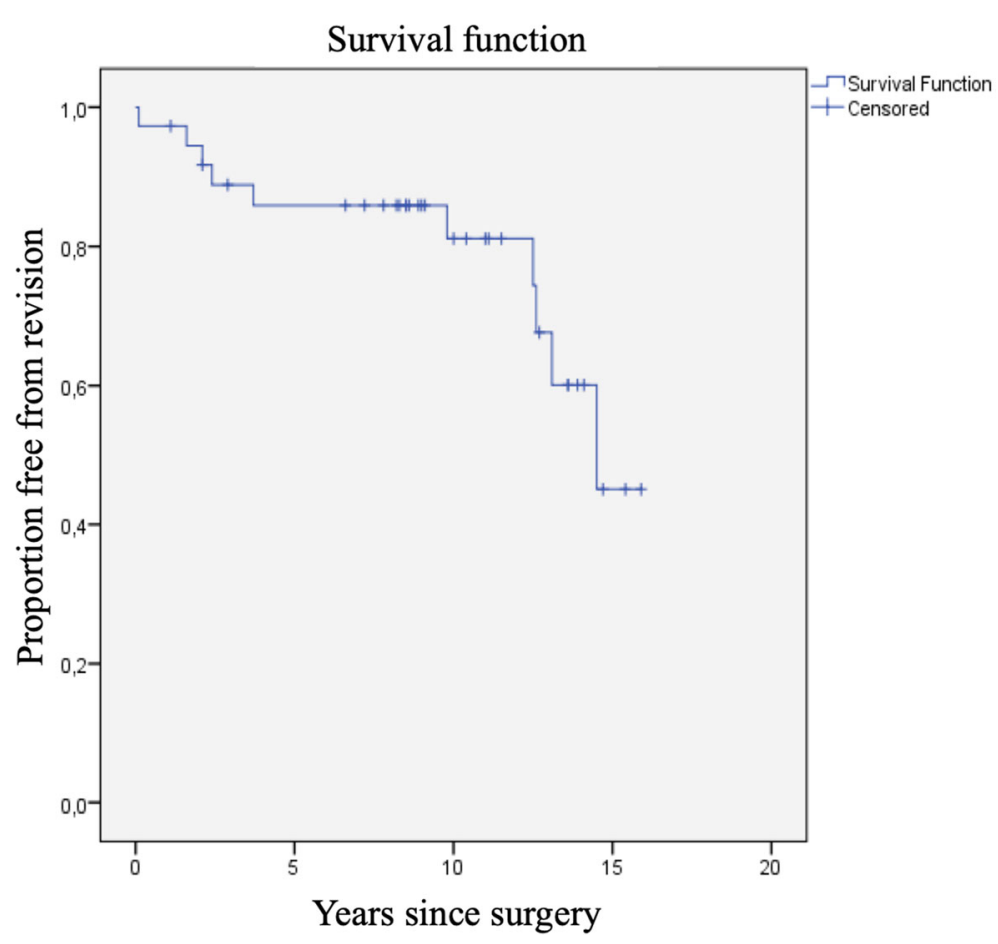

Fig. 4 Kaplan-Meier survival analysis curve with revision for any reasons as an endpoint

\section{Discussion}

The iBP elbow prosthesis is an unlinked prosthesis. The stability of the joint is provided by the soft tissues, therefore the risk of dislocation is higher than in a linked-type prosthesis $[12,13]$. The theoretical advantage of this design is the lower risk of loosening, because of minimal stress on the bone-implant interface [5].

Our study shows survival rates for the iBP elbow prosthesis of 88 and $81 \%$ respectively at 5 and 10 years postoperatively with a progressive decline in survival beyond 10 years. Eleven of 14 patients were satisfied with their elbow as reflected in the scores of the questionnaires. In our study the main reason for revision was loosening

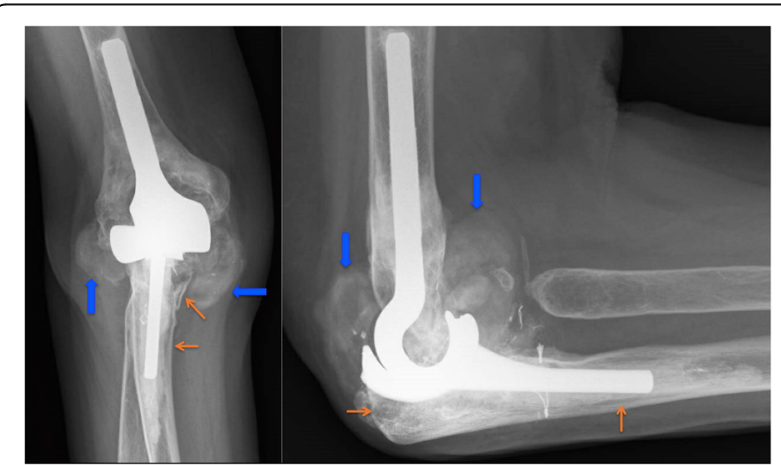

Fig. 5 Radiological signs of PE wear and metallosis. Orange arrows showing radiolucencies, blue arrows showing pseudotumor with polyethylene wear and metallosis (50\%), which is higher compared to the results of Dalemans et al.(33\%), but they only had a follow-up of 7.5 years with their series of the $\mathrm{iBP}$ elbow prosthesis [5, 12, 13]. In their series with the Kudo 5, an unlinked prosthesis with a mean follow-up of 14.5 years, the main reason for revision was loosening and metallosis as well (61\%). The unlinked prostheses were originally developed to render less loosening than linked prostheses, but Voloshin et al. showed in their systematic review no significant

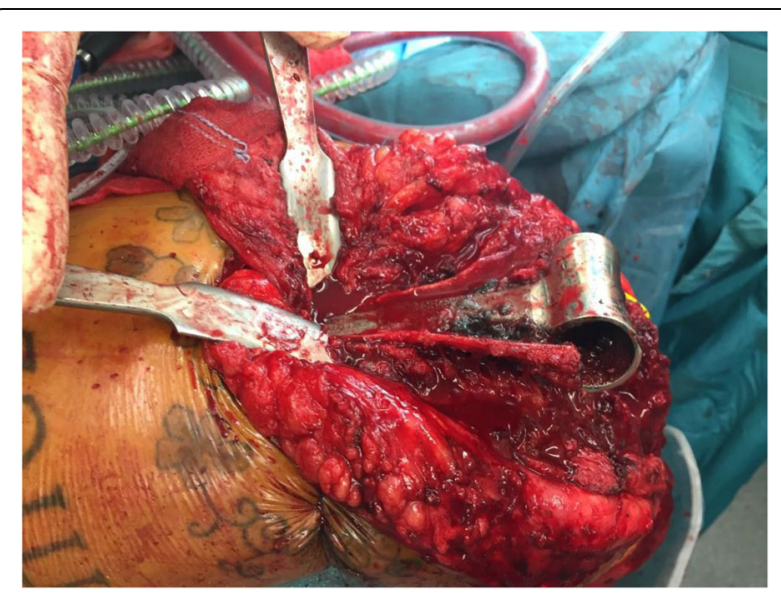

Fig. 6 Revision arthroplasty by humeral osteotomy: severe metallosis 
Table 2 Radiological analysis

\begin{tabular}{|c|c|c|c|c|c|}
\hline Patient & AP humerus & AP ulna & Lat humerus & Lat ulna & Pseudotumor \\
\hline 1 & 5 & 1,3 & & $1,2,3$ & Yes \\
\hline 2 & 1 & & & 3 & \\
\hline \multicolumn{6}{|l|}{3} \\
\hline 4 & & & & 1,3 & \\
\hline 5 & & & & 3 & \\
\hline 6 & 2 & 3 & 2,4 & 1,3 & Yes \\
\hline 7 & 2,4 & 1 & 2,5 & & \\
\hline \multicolumn{6}{|l|}{8} \\
\hline \multicolumn{6}{|l|}{9} \\
\hline 10 & & 1,3 & 1 & 1,3 & \\
\hline 11 & 1 & & 3 & 1 & \\
\hline \multicolumn{6}{|l|}{12} \\
\hline \multirow[t]{2}{*}{13} & 1 & 3 & 1 & 1,3 & \\
\hline & & & 1,2 & 1,3 & \\
\hline 14 & $1,2,5$ & 1,3 & 1,5 & 1,3 & Yes \\
\hline
\end{tabular}

$A P$ anteroposterior, Lat Lateral. Numbers indicate zone of radiolucency as described in Fig. 2

difference in clinically relevant loosening between linked and unlinked elbow prostheses [12].

Over the last years improvements in the quality of PE have been made. A recent study by Popoola et al. [14] showed that vitamin $\mathrm{E}$ blended and crosslinked polyethylene gives lower in vitro wear compared to conventional gamma-irradiated polyethylene in two types of linked, semiconstrained total elbow prostheses. Probably motion in combination with the thin polyethylene in the design of the iBP prosthesis eventually leads to wear, metallosis and loosening.

When revising the iBP we had to revise the ulnar component in 3 of 10 cases.

In 6 of 10 cases persistent instability due to debridement of soft tissue and insufficiency of the collateral ligaments, required revision to a linked-type total elbow prosthesis. In one case a complete iBP revision was performed.

The relatively short survival and the described wear problems and loosening of the ulnar component in combination with the difficulties experienced in revision of an even well-fixed humeral stem have made us decide to stop using this prosthesis.
Another well-known complication after TEA is ulnar neuropathy [15-18]. In our study 3 patients (20\%) had some form of permanent ulnaropathy, despite the ulnar nerve was mobilized and protected during surgery. The reported outcomes on neuropathy after elbow prosthetic joint placement are conflicting. Tanaka et al. did not find ulnaropathy after release of the nerve [18]. On the other hand, not mobilizing the ulnar nerve as shown by Kleinlugtenbelt et al. resulted in $6 \%$ ulnaropathy [4], by Brinkman et al. a high rate of $20 \%$ ulnar neuropathy was found [15]. Postoperative ulnar neuropathy rates appear to vary, so we recommend further research to determine whether mobilization of the ulnar nerve is preferred.

Mean arc of motion in our study was $90^{\circ}$, with a mean flexion of $125^{\circ}$ and a mean extension deficit of $35^{\circ}$. Mean pronation was $70^{\circ}$ and mean supination $75^{\circ}$. Morrey et al. [19] described that the functional arc of motion required for activities in daily life was $120 / 30$ for flexion/ extension and $50 / 50^{\circ}$ for pronation/supination. Five out of 14 patients had a range of motion inferior to this standard. Most of the patients were nonetheless satisfied with their elbow function. 
Few studies have been conducted to determine the long-term outcome of the iBP elbow prosthesis. One study by Kleinlugtenbelt et al. [4] showed a discrepancy between clinical evaluation and radiological signs at short-term follow-up, with a mean follow-up of 4 years. Our study showed this discrepancy too.

Loosening of the ulnar component was seen in $11 \mathrm{pa}-$ tients, although 8 of them did not have any complaints of their elbow. In 9 of these 11 patients radiolucencies around the humeral component were seen. Seven patients had some degree of elbow instability at physical examination without dislocation; 3 of them did show radiological signs of subluxation.

Our current 'care as usual' does not routinely include medium or long term follow-up. The outcome of this study has changed our policy and we routinely do a structural follow-up. Patient related outcome measures only will not be sufficient to assess the integrity of these implants. Following this study, another three prostheses have been revised. All three of them with severe polyethylene wear and metallosis.

\section{Limitations}

We were only able to examine a small number of patients. Our study had a retrospective design, which entailed an important loss of patients. The strength of this study is the length of follow-up.

\section{Conclusion}

We warrant a structural follow-up for all iBP implants, because of the discrepancy between clinical signs and symptoms and radiological loosening, metallosis and consequent progressive bone loss.

\section{Abbreviations}

iBP: instrumented Bone Preserving; OES: Oxford Elbow Score;

DASH: Disabilities of Arm, Shoulder and Hand Outcome Measure; MEPS: Mayo Elbow Performance Score; TEA: Total elbow arthroplasty; VAS: Visual analogue scales; PE: Polyethylene

\section{Acknowledgements}

Not applicable.

\section{Authors' contributions}

All authors have read and approved the manuscript. DM - patient inclusion, patient follow-up, data analysis, writing article. ALB - study design, patient follow-up, writing article. FB - design of the study, acquisition, revising article. DE - analysis, interpretation data, revising article. SKB - study design, interpretation data, revising article. MS - study design, interpretation data, analysis, writing article.

\section{Funding}

There is no funding source.

\section{Availability of data and materials}

The datasets used and/or analyzed are available from the corresponding author on reasonable request.

\section{Ethics approval and consent to participate}

The study was reviewed and approved by the Medical Ethical Committee of University Medical Center Groningen (METc2016/038). The need for consent was waived by the Medical Ethical Committee of University Medical Center Groningen.

\section{Consent for publication}

Not applicable.

\section{Competing interests}

The authors declare that they have no competing interests.

\section{Author details}

${ }^{1}$ Department of Orthopedic Surgery, University of Groningen, University Medical Center Groningen, Groningen, the Netherlands. ${ }^{2}$ Orthopedic Department, Wilhelmina Hospital, Assen, The Netherlands. ${ }^{3}$ Department of Orthopedic Surgery, Amsterdam Medical Center, Amsterdam, The Netherlands. ${ }^{4}$ Orthopedic Surgery Department, Amphia Hospital, Breda, the Netherlands.

Received: 14 January 2019 Accepted: 26 August 2019

Published online: 06 September 2019

\section{References}

1. Fevang BT, Lie SA, Havelin LI, Skredderstuen A, Furnes O. Results after 562 total elbow replacements: a report from the Norwegian arthroplasty register. J Shoulder Elbow Surg. 2009;18(3):449-56.

2. Plaschke HC, Thillemann TM, Brorson S, Olsen BS. Implant survival after total elbow arthroplasty: a retrospective study of 324 procedures performed from 1980 to 2008. J Shoulder Elbow Surg. 2014;23(6):829-36.

3. Pooley J SR. Elbow arthroplasty. A guide for orthpaedic surgeons using the IBP elbow system. Biomet 2000.

4. Kleinlugtenbelt IV, Bakx PA, Huij J. Instrumented bone preserving elbow prosthesis in rheumatoid arthritis: 2-8 year follow-up. J Shoulder Elbow Surg. 2010;19(6):923-8

5. Dalemans A, De Smet L, Degreef I. Long-term outcome of elbow resurfacing. J Shoulder Elbow Surg. 2013;22(11):1455-60.

6. Amirfeyz R, Clark D, Quick T, Blewitt N. Newcastle approach to the elbow, a cadaveric study. Arch Orthop Trauma Surg. 2011;131(6):747-51.

7. Dawson J, Doll H, Boller I, Fitzpatrick R, Little C, Rees J, et al. The development and validation of a patient-reported questionnaire to assess outcomes of elbow surgery. J Bone Joint Surg Br. 2008;90(4):466-73.

8. Veehof MM, Sleegers EJ, van Veldhoven NH, Schuurman AH, van Meeteren $\mathrm{NL}$. Psychometric qualities of the Dutch language version of the disabilities of the arm, shoulder, and hand questionnaire (DASH-DLV). J Hand Ther. 2002;15(4):347-54

9. Turchin DC, Beaton DE, Richards RR. Validity of observer-based aggregate scoring systems as descriptors of elbow pain, function, and disability. J Bone Joint Surg Am. 1998:80(2):154-62.

10. EuroQol - EQ-5D a standardised instrument for use as a measure of health outcome. 2016 Available at: http://www.eurogol.org/home.html.

11. Wagener ML, de Vos MJ, Hannink G, van der Pluijm M, Verdonschot N, Eygendaal D. Mid-term clinical results of a modern convertible total elbow arthroplasty. Bone Joint J. 2015;97-B(5):681-8.

12. Voloshin I, Schippert DW, Kakar S, Kaye EK, Morrey BF. Complications of total elbow replacement: a systematic review. J Shoulder Elb Surg. 2011;20(1):158-68.

13. Ferlic DC. Total elbow arthroplasty for treatment of elbow arthritis. J Shoulder Elb Surg. 1999;8(4):367-78.

14. Popoola OO, Kincaid BL, Mimnaugh K, Marqueling M. In vitro wear of ultrahigh-molecular-weight polyethylene and vitamin E blended highly cross-linked polyethylene in linked, semiconstrained total elbow replacement prostheses. J Shoulder Elb Surg. 2017;26(5):846-54. https://doi. org/10.1016/j.jse.2016.12.066.

15. Brinkman JM, de Vos MJ, Eygendaal D. Failure mechanisms in uncemented Kudo type 5 elbow prosthesis in patients with rheumatoid arthritis: 7 of 49 ulnar components revised because of loosening after 2-10 years. Acta Orthop. 2007;78(2):263-70.

16. Potter D, Claydon P, Stanley D. Total elbow replacement using the Kudo prosthesis. Clinical and radiological review with five- to seven-year followup. J Bone Joint Surg Br. 2003:85(3):354-7.

17. Rahme $\mathrm{H}$. The Kudo elbow prosthesis in rheumatoid arthritis: a consecutive series of 26 elbow replacements in 24 patients followed prospectively for a mean of 5 years. Acta Orthop Scand. 2002;73(3):251-6. 
18. Tanaka N, Kudo H, Iwano K, Sakahashi H, Sato E, Ishii S. Kudo total elbow arthroplasty in patients with rheumatoid arthritis: a long-term follow-up study. J Bone Joint Surg Am. 2001;83-A(10):1506-13.

19. Morrey BF, Askew $L J$, Chao EY. A biomechanical study of normal functional elbow motion. J Bone Joint Surg Am. 1981;63(6):872-7.

\section{Publisher's Note}

Springer Nature remains neutral with regard to jurisdictional claims in published maps and institutional affiliations.

Ready to submit your research? Choose BMC and benefit from:

- fast, convenient online submission

- thorough peer review by experienced researchers in your field

- rapid publication on acceptance

- support for research data, including large and complex data types

- gold Open Access which fosters wider collaboration and increased citations

- maximum visibility for your research: over $100 \mathrm{M}$ website views per year

At $B M C$, research is always in progress.

Learn more biomedcentral.com/submissions 